\title{
Capital de Trabajo
}

\author{
Working Capital
}

\author{
Estefani Olmedo-Lozada ${ }^{a}$, Beatriz Sauza-Ávila ${ }^{b}$
}

\begin{abstract}
:
In order to carry out their functions, companies must have working capital, this refers to the goods, rights and obligations, with which they have, the first that is, the goods and rights are called current assets, example of them are cash and it is usually found in a banking institution, the accounts receivable which represent what the entrepreneur has the right to collect from a third party, the inventories these represent the product offered by the company; On the other hand, economic entities must also comply with their obligations or short-term debts such as those acquired when requesting a bank loan, when buying their product on credit these obligations are called current liabilities, to have healthy finances in an organization You must carry out controls related to your working capital to prevent you from running the risk of running out of cash and for this reason you cannot meet your short-term obligations and this generates the risk of declaring yourself insolvent and illiquid and as a consequence bankruptcy of the same.
\end{abstract}

Keywords:

Assets, liabilities, current.

\section{Resumen:}

Las empresas para poder llevar acabo sus funciones deben contar con un capital de trabajo este se refiere a los bienes, derechos y obligaciones, con los que cuenta, los primeros es decir los bienes y derechos se les denomina activos corrientes ejemplo de ellos son el efectivo y por lo regular se encuentra en una institución bancaria, las cuentas por cobrar las cuales representan lo que el empresario tiene el derecho de cobrar a un tercero, los inventarios estos representan el producto que ofrece la empresa; por otra parte las entidades económicas también deben cumplir con sus obligaciones o deudas a corto plazo como son las que adquiere al pedir un préstamo bancario, al comprar su producto a crédito estas obligaciones se les llaman pasivos circulante, para contar con finanzas sanas en una organización debe llevar controles relacionadas con su capital de trabajo para evitar que corra el riesgo de quedarse sin dinero en efectivo y por tal motivo no pueda cumplir con sus obligaciones a corto plazo y esto genere el riesgo de declararse insolvente y sin liquidez y como consecuencia el quiebre de la misma.

Palabras Clave:

Activos, pasivos, corriente.

\section{Introducción}

Gitman (2007) define al capital de trabajo como los activos corrientes que representan la parte de la inversión que circula de una forma a otra en la conducción ordinaria del negocio, los pasivos corrientes representan a las personas ajenas que financian a la empresa a un corto plazo, por tal motivo en el presente mapa de nombre capital de trabajo se muestra los elementos que lo integran, los tipos de decisiones que pueden adquirir los empresarios ante diversos supuestos del movimiento de recursos financieros que se realizan en una empresa.

\footnotetext{
${ }^{a}$ Universidad Autónoma del Estado de Hidalgo, Email: o1420452@uaeh.edu.mx

b Autor de correspondencia, Universidad Autónoma del Estado de Hidalgo, https://orcid.org/0000-0002-7919-6792, Email: beatriz_sauza@uaeh.edu.mx
} 


\section{Descripción}

El mapa presenta en primer lugar la fórmula del capital de trabajo la cual se describe como activo circulante (caja, bancos, inversiones, clientes, documentos por cobrar, entre otros) meno pasivo circulante (proveedores, documentos por pagar, entre otros) es decir derechos a corto plazo menos las obligaciones a corto plazo. Al no controlar el capital de trabajo se corre el riesgo de que la empresa se quede sin liquidez, uno de los elementos importantes al considerar es la rentabilidad cuya fórmula es ventas netas menos los costos totales, también es importante hablar de los niveles de activos y pasivos, para con ello tomar decisiones, en el mapa se muestran dos tipos de decisiones la liberal y la conservadora, el director financiero debe contar con las habilidades necesarias para poder conducir a la empresa y siempre contar con salud financiera.

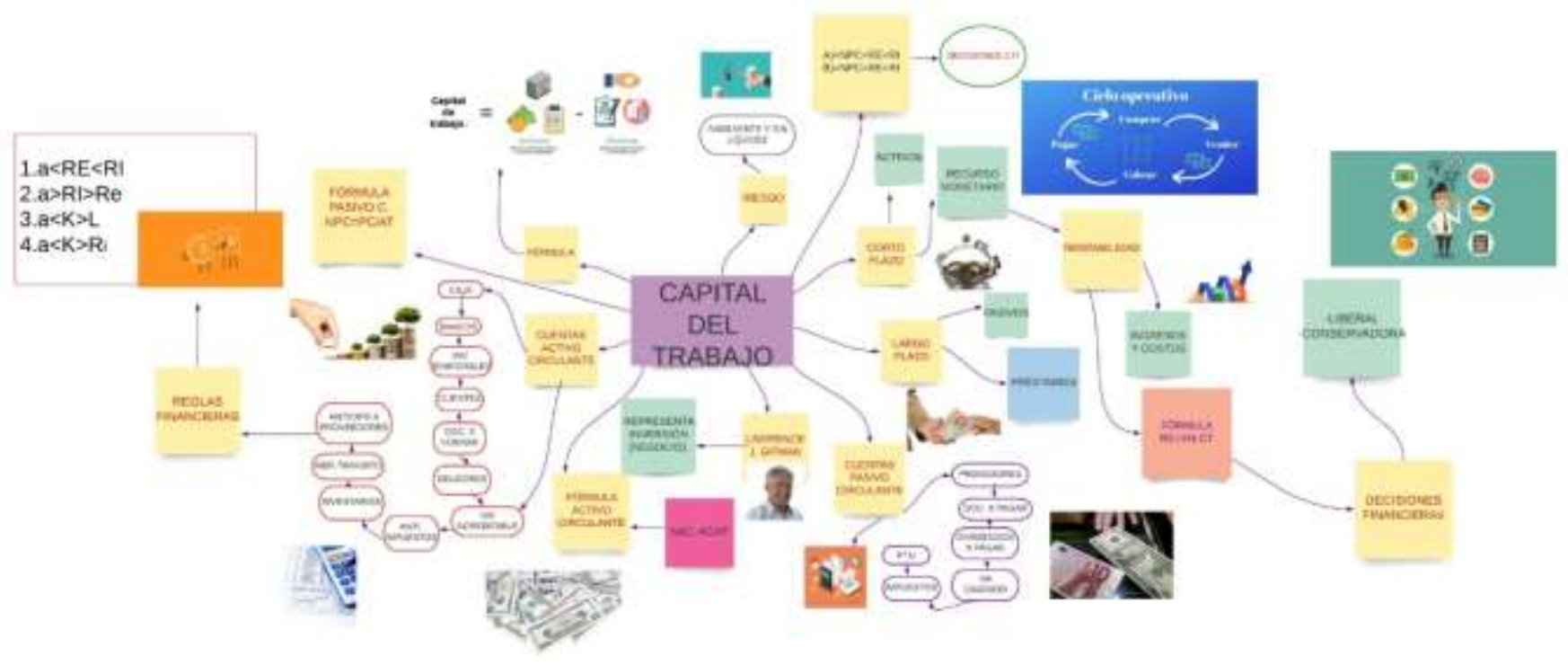

Figura 1. Capital de trabajo

\section{Referencias}

Gitman, L. (2007) Principios de administración financiera, Pearson.

Robles, C.L. (2012). Fundamentos de Administración Financiera. Red Tercer Milenio. 